\title{
Artículos
}

Encuentro №. 98, 6-29, 2014

\section{Escrituras subversivas: pensamiento crítico desde Centroamérica}

\author{
Juan Pablo Gómez y Bradley Hilgert ${ }^{* *}$
}

\section{Recibido: febrero de 2014 / Aceptado: julio de 2014}

¿Qué significa escribir durante la guerra? ¿Qué posicionalidades y sensibilidades se producen a partir de estas experiencias límites y de qué forma nos pueden ayudar a comprender el pasado y el presente? Para responder estas preguntas analizamos la política de escritura de tres pensadores centroamericanos: Ignacio Martín-Baró, Ricardo Falla e Ileana Rodríguez. A través del método etnográfico de la historia propuesto por Cristina Rivera Garza, postulamos que estos intelectuales nos permiten establecer un puente para presenciar el pasado. Cada uno de ellos nos ofrece una imagen del pasado reciente de tres países de la región. El pensamiento producido desde Centroamérica durante los contextos revolucionarios y de guerra nos permite dialogar críticamente con el pasado, a la vez que nos da luces para pensar los cambios que continúan pendientes hoy.

Palabras clave: pensamiento centroamericano/ memoria/ historia/guerra

* Instituto de Historia de Nicaragua y Centroamérica, Universidad Centroamericana (IHNCAUCA) y The Ohio State University. Correo electrónico: juanpablo.gomez@ihnca.edu.ni

** Departamento de Español y Portugués, The Ohio State University. Correo electrónico: hilgert.7@ osu.edu 


\section{Introducción}

La reflexión que presentamos aquí es fruto de un seminario de posgrado que dictamos a través de la plataforma virtual del Consejo Latinoamericano de Ciencias Sociales (CLACSO). ${ }^{1}$ En dicho curso estudiamos los puntos nodales en el pensamiento centroamericano con el objetivo de dar a conocer y analizar los procesos recientes que han impactado a la región, así como las principales trayectorias que la han formado. Las bibliografías del curso fueron seleccionadas según su capacidad de trazar una genealogía de cómo los y las pensadoras de la región entienden a las sociedades centroamericanas. Elegimos una muestra de intelectuales destacados de la región para mostrar el pensamiento centroamericano en torno a cuatro aspectos centrales: 1) las bases coloniales de nuestro tiempo; 2) la relación entre violencia, política y genocidio; 3) las revoluciones en Centroamérica; y 4) los momentos de posguerra y transición. Si bien en un primer artículo en el número anterior de Encuentro nos centramos en el segundo aspecto en el contexto específico de la historia reciente de Guatemala (Gómez \& Hilgert, 2014), en el presente trabajo nos movemos a lo escrito durante los momentos bélicos en El Salvador, Guatemala y Nicaragua. Lo que exponemos a continuación son los primeros resultados de este proyecto de pensamiento que anhela plantear el estudio de la región centroamericana como fundamental para entender la diversidad de dinámicas que constituyen Latinoamérica.

Hay muchos análisis significativos que nos ayudan a entender los conflictos armados centroamericanos y, más ampliamente, la historia reciente de la región. Por ejemplo, Andrés Pérez Baltodano (2003) sitúa la revolución nicaragüense en su historia nacional y aboga por la inclusión de la dimensión cultural en el análisis del acontecimiento en su libro Entre el Estado conquistador y el Estado nación: providencialismo, pensamiento político y estructuras de poder en el desarrollo histórico de Nicaragua. Para profundizar la comprensión de la guerra en Guatemala podemos apoyarnos en las investigaciones del equipo de imaginarios sociales de la Asociación para el Avance las Ciencias Sociales en Guatemala (AVANCSO), en particular en Glosas nuevas sobre la misma guerra (2009). Para el caso de la guerra civil salvadoreña, Mario Lungo aporta un libro comprensivo con su El Salvador en los años 80: Contrainsurgencia y revolución (1991). También podemos estudiar un libro fundamental como es Revoluciones sin cambios revolucionarios de Edelberto Torres-Rivas (2011), para entender las revoluciones en el contexto regional y para una reflexión crítica sobre las dificultades para conseguir cambios profundos estructurales. Todas estas bibliografías ofrecen meditaciones novedosas e importantes para entender la coyuntura por la cual nos preocupamos en este artículo. Sin embargo, nuestra mirada busca otras posiciones enunciativas y analíticas. Nuestro interés, si bien es

\footnotetext{
1 Seminario 1321, otoño 2013, "Pensamiento centroamericano". El equipo docente del seminario estuvo constituido por Ileana Rodríguez, Juan Pablo Gómez y Bradley Hilgert. Contó con la participación de más de 30 estudiantes de distintos países de Latinoamérica. Agradecemos a Ileana Rodríguez, profesora principal del seminario, por su motivación y su seguimiento atento a nuestro trabajo; al Instituto de Historia de Nicaragua y Centroamérica (IHNCA-UCA), centro miembro de CLACSO del cual surgió la iniciativa del curso; y a las y los estudiantes del seminario, cuyo interés, aportes, dudas, inquietudes e incluso sensibilidad, motivaron estas reflexiones.
} 
por la historia reciente, se desarrolla de otras maneras. Nuestras preguntas son otras. En parte, nuestras inquietudes surgen de diferencias generacionales. No vivimos en carne propia los procesos sociales de los que aquí nos preocupamos, pero sí vemos su impacto en las sociedades centroamericanas. Queremos conocer no solo los hechos, datos, teorías y consecuencias de los años 70 y 80 , sino que también queremos sentir la experiencia vivida y sus e/afectos.

Este trabajo es un ejercicio para dar salida a estas preocupaciones, interrogándonos sobre cómo la guerra afectó a los/las intelectuales y al pensamiento crítico, para así entender mejor nuestros presentes. Para ello, nos planteamos las siguientes preguntas: ¿Qué significa escribir durante la guerra, en el mismo momento en que el genocidio se materializa, o en el instante en que, con incredulidad y rabia, vemos los efectos de la guerra sobre los cuerpos? ¿Qué dimensiones adquiere el pensamiento al atestiguar el horror de la política devenida en violencia desnuda? Estas preguntas desean llamar la atención sobre la particularidad de las circunstancias límite que rodearon la producción de pensamiento en el contexto de los conflictos armados y episodios bélicos de la historia reciente centroamericana.

Queda mucho por analizar en torno a la manera en que la academia de las humanidades y las ciencias sociales fue afectada por el panorama de guerra y muerte de la región. En nuestro propósito de explorar la producción de pensamiento desde Centroamérica, consideramos clave preocuparnos no solo por qué se piensa, sino también con quién y desde dónde se piensa; cuándo y cómo se produce el pensamiento; cuáles son las temporalidades, sensibilidades y fragilidades que lo acuerpan. Las posicionalidades y sensibilidades que elegimos estudiar aquí representan una excelente oportunidad para pensar las interrogantes anteriores y también para entrar a un terreno que es el de las políticas de la escritura.

Para desarrollar lo anterior visitamos el pensamiento de tres intelectuales centroamericanos, académicos y sujetos activos ellos mismos del pasado reciente centroamericano: Ignacio Martín-Baró, Ricardo Falla e Ileana Rodríguez. Cada uno es representativo de uno de los tres países de la región que estuvieron en guerra por los procesos revolucionarios emprendidos. Hemos elegido a estos autores porque vivieron de forma activa y altamente comprometida los conflictos y cambios de cada una de las sociedades sobre las cuales reflexionaron. Pensaron y vivieron sus realidades de una manera profunda que se refleja en sus textos. No limitaron su pensamiento a las pretensiones de objetividad, ni a las estructuras rígidas científicas y académicas. Escribieron desde sus entrañas, desde experiencias vividas y dolorosas. Su escritura camina de la mano con los conflictos armados. Su pensamiento es entonces altamente contextual, en el sentido de que fue producido casi-a-quema-ropa. Tal intensidad los retó a vencer barreras epistémicas y éticas: narrar lo inenarrable; conceptualizar el horror que atestiguaron, escucharon, vieron-son los casos de Martín-Baró y Falla. En el caso de Rodríguez, como veremos, es un pensamiento que revisita la experiencia revolucionaria, la suya propia y la de todo un pueblo, pero lo hace apoyándose en otras epistemologías, no lineales sino circulares; no masculinas sino feministas. El resultado es una reescritura crítica del pasado revolucionario. En los tres casos son realidades recién pasadas, no solo en términos históricos sino recién pasadas por el cuerpo mismo de quienes las escribieron. Nuestra tesis es que es un pensamiento sentido-en-el-cuerpo. El pensamiento puede ser algo desolador. 
Tener conciencia de ello y no bajar la guardia no es otra cosa sino una elección de vida.

Sus textos pueden ser estudiados en más de una manera. Se les puede leer como pensamiento académico, e integrarlos a campos específicos de conocimiento. Pero también podemos proponer una lectura etnográfica de los mismos, apoyándonos en lo que por ello entiende Cristina Rivera Garza. Más que leer sobre el pasado, ella propone "establecer una relación dialógica, interactiva, presencial, con información que viene del pasado y desde el pasado en forma escrita” (2008, p. 172). Es esta justamente la relación que deseamos entablar con los autores. Visitar sus ideas con el ánimo de escuchar las voces del pasado, tocar los cuerpos heridos, sentir el pasado reciente aun si no lo hemos vivido. Martín-Baró, Falla y Rodríguez no solo nos brindan valiosas herramientas intelectuales para entender los rasgos particulares de un período de nuestra historia. También nos abren la posibilidad de presenciar el pasado. Si hacemos énfasis en escuchar, tocar y sentir es porque queremos invitar a los y las lectoras a utilizar más de uno de sus sentidos al conectar con el pasado. Queremos acercarnos a la intensidad de sus palabras, de su pensamiento y escritura, tal y como plantea Rivera Garza:

A lo que aspiro es a producir un texto de historia que sea al mismo tiempo, y aquí tomo este término del bagaje del arte contemporáneo, un texto procesual -un artefacto cultural en el que no sólo importe la información contenida en él, sino también la manera en que tal información se produjo. Si esto es del todo posible, la información cesará de ser información para convertirse en otra cosa -un puente, una reverberación, un gozo. Un gozo de la vista y, con suerte, con pericia, con buen afán, un gozo, también del oído. Un gozo de la presencia. Un gozo, en otras palabras (siempre en otras palabras), imposible (2008, p. 178).

Si los visitamos de esta manera escucharemos un aviso de incendio; voces que alertan sobre las nefastas consecuencias que la guerra estaba dejando a nuestras sociedades, sobre los efectos de la misma sobre las mentes y cuerpos de las personas afectadas. Este ensayo es un intento de escucharlos, no de estudiarlos. Con tal gesto queremos mostrar cómo el pensamiento centroamericano contribuye a la comprensión del pasado reciente, no solo como conocimiento académico, sino como posicionalidad/sensibilidad ante la historia y la realidad. Como iremos viendo, en su escritura se unen el ánimo documental con una actitud ética y una profunda preocupación por la construcción de sociedades democráticas, y el pensar la política como dignificación de la vida y de las relaciones sociales. Queremos entonces responder a las siguientes preguntas: ¿Qué tipo de puente, de reverberación hacia el pasado encontramos en el pensamiento de estos tres intelectuales centroamericanos? ¿A qué imágenes y voces nos dan acceso para sentir el pasado? 


\title{
2. Violencia, deshumanización, trauma: primera imagen-Martín-Baró
}

\author{
"No son las realidades las que se cuentan, \\ sino las imágenes” (Martín-Baró, 1988, p. 73).
}

¿Cómo puede decirse que El Salvador es una 'incipiente democracia', cuando lo que vivimos día a día es un país en guerra civil? El pensamiento de Martín-Baró desdice y denuncia. En La violencia política y la guerra como causas del trauma psicosocial en El Salvador (1988), ensayo escrito poco más de un año antes de ser asesinado, desdice la imagen proyectada y difundida por la administración norteamericana de Ronald Reagan sobre El Salvador. En esta imagen, El Salvador era representado como "el mejor ejemplo de las 'nuevas democracias' latinoamericanas que habrían ido surgiendo en la última década, en particular en el área centroamericana, donde sólo Nicaragua constituiría la excepción” (1988, p. 66). Denuncia los propósitos del gobierno norteamericano al construir tal imagen: legitimar su política exterior, así como el financiamiento al ejército salvadoreño y frenar el 'avance del comunismo' en América Latina.

¿Cuáles eran, a saber de Martín-Baró, los datos con los cuales la administración Reagan sustentaba su afirmación? Eran cuatro: la realización de un proceso electoral en el año de 1988; el 'creciente respeto' a los derechos humanos de la población; el avance en la profesionalización del ejército salvadoreño, subordinándose al poder civil y; en cuarto lugar, el mejoramiento en la satisfacción de las necesidades básicas de la población, a pesar de los problemas generados por los "grupos marxistasleninistas que practican el terrorismo violento con el apoyo de Cuba y Nicaragua” (1988, p. 66).

Martín-Baró entra en polémica con esta imagen y la califica como "una elaboración ideológica muy propia del gobierno de Reagan, pero que poco o nada refleja la situación de El Salvador" (1988, p. 66). Él deconstruye esta imagen señalando que el carácter democrático de un gobierno no depende solamente de si fue o no elegido en un proceso electoral. Más que eso, considera necesario preguntarse cuáles son las fuerzas que diariamente determinan la actuación, el proceder de tal gobierno. Al llevar su pregunta a la realidad social, en lugar de encontrar una nueva democracia, encuentra que en El Salvador "cuentan más los fantasmas de la 'seguridad nacional' norteamericana que las necesidades más básicas del pueblo salvadoreño” (1988, p. 66). Su imagen, como podemos ver, es muy distinta. A continuación se pregunta, “CCuál es entonces la realidad de El Salvador?”. Las respuestas que dio a estas preguntas se adentran en la diariedad de la guerra salvadoreña, y son nuestro terreno exploratorio para contestar a nuestra pregunta sobre cuál o cuáles son las imágenes del pasado que hoy -es decir, preguntando desde el presente- podemos encontrar en el pensamiento de Martín-Baró. Veamos a continuación. 


\subsection{Primera imagen: Chalatenango}

Cada vez que se inicia un operativo, la población se cobija en sus casitas, agarrotada por una serie de síntomas psicosomáticos: temblor generalizado del cuerpo, "flojera" muscular, diarrea... Un matrimonio ya anciano ha optado desde el comienzo de la guerra por esconderse en un "tatú" o refugio cada vez que se produce un operativo o que se acerca la Fuerza Armada al lugar. El resultado ha sido que el solo anuncio de un operativo le produce al señor lo que todo el pueblo conoce como "el dolor": un violento retortijón intestinal, un abrumador dolor de cabeza y una flojera generalizada que no le permite ni caminar (Martín-Baró, 1988, p. 67).

Qué vemos aquí sino una manifestación extrema del miedo en la mente, los cuerpos y los órganos de los pobladores de este pueblo ubicado al norte de El Salvador. El miedo no es una postura racional. No estamos en los dominios del cálculo y el razonamiento. Es, más bien, la pérdida del control sobre el propio cuerpo y la mente, y el abandono involuntario a sus reacciones primarias: temblor, retortijones intestinales, diarrea. Así, la historia del pasado bélico es más que las palabras sobre una página en un libro de texto. Es más que una lista de acontecimientos y muertos. La historia, cuando es una historia vivida, cuando es memoria-reverberación, es justamente estas imágenes, estos conocimientos del cuerpo, estos efectos y afectos, ¿lo pueden sentir? A través del método etnográfico convertimos la escritura en voces, en un puente al pasado, reviviendo en nosotros el mismo dolor en las entrañas, los mismos a/efectos corporales.

\subsection{Segunda imagen: Usulutlán, sureste del país}

Se trata de territorios-imagen de las economías monoexportadoras centroamericanas. Hay producción de algodón en la zona costera y de café en la zona montañosa. Veamos cómo nos presenta esta imagen:

los soldados gubernamentales practican en forma sistemática el abuso sexual de las mujeres campesinas jóvenes que viven en la zona. Para evitar las continuas violaciones masivas, las "más listas" tienen que recurrir a la protección de algún soldado u oficial, prostituyéndose con ellos y pidiéndoles que las defiendan de los demás (Martín-Baró, 1988, p. 68).

¿De qué nos habla esta imagen? Es una imagen de la violación utilizada como arma de guerra. A través de ella podemos presenciar cómo los soldados -hombres todos- afirmaban su superioridad sobre las mujeres a través de una dominación sexual. Nos enseña la violencia como asunto de masculinidades. Pero es también, como la anterior, una prueba viva del miedo. En este caso de las mujeres a ser violadas masivamente, lo que les llevaba a permitir a un soldado apropiarse de su cuerpo y disponer de él. 


\subsection{Tercera imagen: lugar - una casa, un bus, una fiesta}

matanzas de civiles realizadas por soldados de permiso o exsoldados que arrojan granadas a una casa particular, en un bus o en medio de un baile. (...) Los motivos suelen ser celos o deseo de afirmar su poder o 'autoridad' (Martín-Baró, 1988, p. 69).

Hasta la guerra tiene un protocolo legal y procedimental a seguir. Pero aquí tal cosa no existe. La guerra es simplemente una violencia criminal desbordada. Si la imagen anterior evidenciaba una superioridad masculina que manifiesta como violencia de género, aquí tenemos otra expresión de la misma masculinidad violenta. Pero es más que eso. Es una violencia sin razón. Cuando escuchamos las voces de la historia con este pasaje, nos acercamos más a la presencia de esta experiencia: masculinidades arcaicas e impunes que pueden irrumpir en cualquier momento y en cualquier espacio - público o privado. Perdemos entonces cualquier sensación de normalidad y seguridad. Este no es el mejor ejemplo de las 'nuevas democracias' de la región.

\subsection{Cuarta imagen: lugar - escuelas públicas y privadas}

Entrevistas con 200 niños. En 1987 tratan de imitar un estudio de los Estados Unidos sobre la formación del concepto de clase social al entrevistar a niños y niñas de diferentes sectores sociales. Lo asombroso y alarmante de los resultados es la respuesta de varios entrevistados a la pregunta "¿Qué tendría que pasar para que no hubiera pobres?" 'De la boca de los niños' sale la respuesta escalofriante: "matarlos a todos" (Martín-Baró, 1988, p. 68). Esto es lo que Martín-Baró llama la militarización de la mente. Inmediatamente tenemos una imagen que contradice cualquiera que intenta presentar un El Salvador democrático, respetuoso de los derechos humanos y con un buen funcionamiento del sistema de justicia. La imagen de Martín-Baró es otra:

No hay que olvidar que algunos sectores de la sociedad salvadoreña todavía plantean como solución a la guerra civil la eliminación de 'todos los subversivos' a la manera de 1932, para 'ganar de este modo'-o al menos así lo afirman-'otros cincuenta años de paz' (1988, p. 69).

¿Somos capaces de escuchar estas voces juveniles del pasado y no conmovernos? ¿Podemos ver estas imágenes y no sentir el pasado en el presente? En esta dirección nos lleva la política de escritura de Martín-Baró. El punto no es simplemente contar y denunciar sino compartir sensibilidades para cambiar el presente.

\subsection{Las imágenes de Martín-Baró: cómo nos tocan y desafían}

Estas imágenes, la de los síntomas psicosomáticos, la de las violaciones masivas, la de la violencia criminal desbordada y la de la militarización de la mente, son el apoyo de Martín-Baró para evidenciar que "la realidad de El Salvador es muy distinta a la ofrecida por los informes oficiales del gobierno norteamericano" (1988, p. 69). Y es importante disputar las imágenes de la guerra - como hoy con 
las imágenes del pasado que circulan en el discurso público - porque ellas forman parte activa de la guerra misma. En palabras de Martín-Baró, "el ocultamiento sistemático de la realidad sigue siendo una de las características fundamentales de la guerra salvadoreña" (1988, p. 73). Por tal razón, a contrapelo de la narrativa norteamericana, él propone tres rasgos que definen la realidad salvadoreña en ese momento: 1) el creciente empobrecimiento de la población, 2) la vigencia de la autoridad por encima de la ley - pensemos por ejemplo en los abusos de poder de los soldados antes mencionados - y 3) la continuidad de la guerra civil.

¿Cuál es la imagen del pasado que Martín-Baró nos transmite y hereda para los que queremos comprenderlo desde el presente? Con el primero de sus puntos, el del creciente empobrecimiento, nos habla realmente de un pasado-presente: la situación de sobrevivencia en que se encuentra gran parte de la población. La imagen es la de una sociedad que no ha sido capaz de asegurar la sobrevivencia mínima de su población, el derecho fundamental a tener vida, a conservarla, a comer lo necesario para no morir. A ese respecto discute una escena que continúa formando parte de la diariedad salvadoreña y centroamericana: la falta de un consenso en torno a qué derechos deben ser más resguardados. Si interesa más proteger la propiedad privada y la libertad de prensa, que el derecho a comer y tener un techo. La propiedad privada continúa siendo un derecho más resguardado que el derecho social a tener una vivienda ${ }^{2}$. Esto se evidencia tanto en las normativas constitucionales como en el discurso público. La imagen fundamental que nos proporciona Martín-Baró es la de una sociedad "empobrecida, no solo dividida, sino violentamente desgarrada, en la que los derechos humanos más básicos de las mayorías son estructural y sistemáticamente negados" (1988, p. 69). Pensemos que Martín-Baró nos brinda esta imagen no solo como académico, sino también como testigo de esos tiempos, testimonio de vida, ser humano comprometido con la dignificación de la vida del pueblo salvadoreño.

En el segundo punto que desarrolla, la preeminencia de la autoridad por encima de la ley, nos vamos a encontrar nuevamente con la imagen de una sociedad en profundo estado de miedo. ¿Quién produce tal miedo? A saber de Martín-Baró, "la fuerza armada gubernamental sigue representando para la mayoría de los salvadoreños un poder atemorizante y abusivo, la 'autoridad' arbitraria y omnipotente" (1988, p. 70). Es el poder emanado del miedo, y no de la legalidad ni legitimidad dada por la población. Es también, como vimos antes, la utilización de una figura de autoridad armada para apropiarse de los cuerpos de las mujeres. El miedo se instala y se queda en los cuerpos a través de las armas y de las violaciones masivas, grupales, que nos hablan de estas acciones no solo como burocráticas - 'banalidad del mal' podría decir Hannah Arendt-, sino de la existencia de un goce al realizarlas. Otra vez, el aporte del pensamiento de Martín-Baró aquí es la forma en que su escritura trasciende las versiones objetivistas y cuantificadoras del pasado para entrar en los aspectos afectivos y no-racionales -sobre todo el miedo- del conflicto bélico y las formas en que la guerra afectó las vidas cotidanas de los salvadoreños. No es la Historia académica tradicional que nos brinda, sino unas imágenes palpitantes

2 Esta es la crítica aguda del colega y compañero de Martín-Baró, Ignacio Ellacuría (1991). 
que muestran los aspectos vividos, existenciales, afectivos de vivir en tiempos de guerra. Al atinar el trauma psico-social de la guerra de esta forma también nos toca, nos hace sentir el pasado-presente con nuestras mentes, nuestros ojos, nuestros oídos y nuestros cuerpos.

En su tercer punto encontramos una imagen penetrante del pasado reciente: el país destruyéndose a causa de la guerra. Tal destrucción es de doble naturaleza. Es corporal, en términos del alto número de víctimas que está causando la guerra -Martín-Baró menciona setenta mil muertos en los últimos años del conflicto. Pero la destrucción también es psicosocial. Y esta naturaleza es igual o incluso más devastadora que la anterior. Esta destrucción se aloja en el cuerpo, en los órganos, y se instala en la mente; militariza la mente. En palabras de Martín-Baró, "el impacto de la guerra salvadoreña va desde el deterioro orgánico que aparece en los síntomas psicosomáticos hasta la criminalización aberrante en la mente infantil pasando por el desquiciamiento de las relaciones sociales" (1988, p. 70).

Bien podemos pensar que en la criminalización de la mente infantil encontramos la guerra como herencia social a las nuevas generaciones; aquellas que no vivieron la guerra en carne propia, que no sintieron los síntomas orgánicos en su propio cuerpo, pero que llevarán a cuestas el enorme reto de desmilitarizar la psiquis individual y colectiva, y de pensar cómo construir un lazo social diferente al constituido por la guerra. Desde nuestra perspectiva, este es uno de los aspectos por los cuales Martín-Baró afirma que la guerra amenazó la "viabilidad histórica" del país (1988, p. 70). También fue una amenaza para la 'viabilidad histórica' de la sociedad salvadoreña en su conjunto porque la guerra no es una simple disputa entre rivales. Y este es el momento en que podemos ver el miedo del que hemos hablado antes en las palabras mismas de Martín-Baró, en su propio pensamiento. Si en lugar de leer, escuchamos atentamente su pensamiento, podemos sentir su miedo a la guerra. ¿Por qué razón? Por su "carácter definidor del todo social” (1988, p. 71).

El temor de Martín-Baró radica en la fuerza de la guerra para "convertirse en el fenómeno más englobante de la realidad de un país” (1988, p. 71) y supeditar a su espiral destructiva toda una naturaleza de fenómenos sociales, políticos, culturales. Carl Schmitt diría que la guerra es justamente cuando con mayor intensidad se manifiesta lo político (2007, p. 45). Pero a diferencia de la naturalización pragmática de la guerra en Schmitt, en Martín-Baró lo que escuchamos es el aviso desesperado de una catástrofe, un no-aguantar-más; llevar a la escritura los límites mentales y corporales de la violencia, e interpelarnos sobre la necesidad de construir otros métodos de resolver los antagonismos de lo político.

Claro está que la guerra no absorbe de igual manera a toda la sociedad. Unos la viven más de cerca que otros. Cuando Martín-Baró visibiliza esto, escuchamos una rabia en su escritura, quizá debido a la falta de empatía y sordera que una parte de la sociedad salvadoreña tenía hacia la población más afectada diariamente por la guerra. Su rabia consiste en el reconocimiento de que la guerra hace que unos celebren una nueva vida en la muerte de otros. No es lo mismo vivir la guerra "en carne propia” que vivirla a través de las pantallas de la televisión, tal y como la “contempla el burgués industrial” (1988, p. 71). ¿No todos sintieron el miedo en sus cuerpos? ¿Lo sintieron quienes contemplaron la guerra de largo? ¿Podría expresarse el miedo en la ausencia de empatía, en la inmovilización? 
Escribir durante la guerra es para Martín-Baró pensar a contrapelo de la "historia oficial" que construye imágenes distorsionadas de la realidad y que encubre los actos criminales de las fuerzas armadas que antes tuvimos oportunidad de conocer. Para él, el pensamiento crítico en tiempos de guerra debe ser un pensamiento subversivo -en términos de subvertir "el orden de mentira establecido" (1988, p. 73); un pensamiento que se arriesga a llevar las consecuencias de ser catalogado en ese momento como subversivo, que no era otra cosa que estar marcado para ser eliminado. Su trabajo también tiene la virtud de ser sensible a los cambios profundos que el fenómeno de la guerra produce en una sociedad y que nos permiten tener una idea del peso que este pasado reciente puede tener para la realidad de hoy. En este caso, la principal consecuencia es "una militarización de la sociedad y de la vida colectiva" (1988, p. 76). La intensidad de lo político estaba absolutamente en lo militar. No había política como deliberación. Solamente violencia desbordada visible como síntoma corporal, sistema nervioso destruido, descomposición humana.

¿Consideraron los acuerdos de paz la intensidad con que se militarizó la sociedad salvadoreña y las consecuencias para las generaciones futuras del país? ¿La pacificación significó la desmilitarización de las mentes? Creemos que el presente nos da un no por respuesta. Al contrario, el pensamiento de Martín-Baró nos habla de un pasado que perdura y se extiende temporalmente como trauma psicosocial, esto es, como "residuo permanente", "herida" (1988, p. 77). Él le imprime al trauma psicosocial un carácter dialéctico y relacional. La herida es relacional porque no se imprime únicamente en la ciudadanía afectada, víctima directa de la violencia, sino que se manifiesta como relación social enajenante. Un ejemplo es la negación del "carácter humano del 'enemigo' al que se rechaza como interlocutor y al que se busca destruir" (1988, p. 80). Por tal razón trazó como reto de la sociedad una 'tarea psicosocial' orientada a la transformación de las relaciones sociales.

Estas imágenes de Martín-Baró son imágenes que nos tocan y nos desafían porque llevan el pasado al presente para "establecer un nuevo marco para la convivencia, un nuevo 'contrato social' (...) de manera que la convivencia se funde en la complementariedad mutua" (1988, p. 83). Visitar su pensamiento aporta a no olvidar esa catástrofe hoy ni los retos aún pendientes. Es un insumo para problematizar la historia oficial de la postguerra y los cauces institucionales a través de los cuales se ha llevado a cabo la desmilitarización de las mentes y los cuerpos. Hay que recordar, también, que en su pensamiento la transformación de las relaciones sociales pasaba necesariamente por la realización de los derechos humanos a la vida, a la alimentación, a la vivienda, dimensiones tan básicas de la vida pero que al día de hoy no hemos sido capaces de resolver como sociedad. Pensar a Martín-Baró es visitar la memoria de una vida marcada por la misma catástrofe que anunció; rememorar una vida dañada por la intensidad de una política de muerte. 


\title{
3. Anunciar la vida; narrar lo (in) creíble: segunda imagen-Ricardo Falla
}

\author{
“¡Y cómo es eso del destace?, pregunté al testigo. \\ ¿Cómo es eso de los dos matagentes?"
}

(Falla, 1992, p.i)

Si un pensador centroamericano desarrolló el sentido de la escucha durante los conflictos armados pasados, fue Ricardo Falla. Su investigación, Masacres de la selva, fue una de las primeras documentaciones de los investigadores sociales guatemaltecos de las masacres que estaban ocurriendo en el país. Su trabajo es pionero pues documentó el 'horror', como él mismo lo llama, antes de iniciativas institucionales posteriores, como por ejemplo el Proyecto Interdiocesano de Recuperación de la Memoria Histórica (REMHI).

El método de Falla - que aquí nombramos como política de escritura nos da acceso a las voces del pasado. Él convierte el quehacer antropológico en puente a la historia y experiencia viva. Como Martín-Baró, Falla quiere denunciar. Pero mientras el primero invocó imágenes de la diariedad, cuerpos somatizados, el segundo invocó las voces de la historia, ofreciéndonos hoy un acceso directo a ellas.

En la introducción a Masacres de la selva Falla se hace una pregunta clave para los propósitos de este ensayo: “¿Para qué escribir sobre masacres? ¿Para qué recordar esas crudezas y crueldades sin cuento?” (1992, p. ii). Leamos su respuesta y pongamos atención detenidamente a cómo informa sobre su política de escritura:

el testigo nos da la clave. El testimonio, salido del fondo de su memoria emocionada - "nunca lo olvidaré"-, anuncia una realidad existencialmente positiva para él: estoy vivo. Su testimonio es una buena noticia. Mientras más terrible es la narración de lo que se presenció, más maravillosa es la realidad que anuncia: estoy vivo (1992, p. ii).

Falla escribe sobre masacres para dar a conocer la voz de cientos de testigos que "quieren decir al pueblo de Guatemala y a las naciones del mundo: estamos vivos, increíblemente, estamos vivos” (1992, p. ii). Asume la labor de los evangelistas, como él mismo reconoce - "nos parecemos al evangelista Marcos, que narró la buena nueva sin ser testigo inmediato" (1992, p. ii) -, y anuncia la vida que ha sobrevivido a una voluntad arrasadora cuyo propósito era no dejar rastro alguno. He aquí el propósito del pensamiento crítico: no documentar la muerte, sino la vida. No hay mayor resistencia al poder de muerte que un aliento de vida, un cuerpo viviente. La vida es potencia en sí misma y en este caso potencia-semilla del pensar crítico; sentido del para qué y con quiénes pensar; acceso epistémico y afectivo a un intermundo, el de los vivos y el de los muertos. Las voces de los sobrevivientes cabalgan en más de un mundo, cuestión que es una amenaza mayor al poder.

Falla es entonces un "intermediario del asunto" (1992, p. ii); no es testigo directo pero la historia lo convirtió en un sujeto de enunciación clave: su escritura puede transmitir la voz, la memoria de los testigos, lo que estos vieron, oyeron, 
tocaron, sintieron. Si pensamos nuevamente en Martín-Baró, las voces intermundo desdicen con su propia experiencia la mentira institucionalizada, la historia oficial, y nos introducen a otra dimensión del ser y pensar que en Falla está relacionada a la fe. Es la fe, en términos de la suspensión de la razón empírica, la que permite al lector entrar en una relación plena y dialógica con estas voces de la historia que nos hablan de su pasado increíble. Tomemos el lugar de Falla como sujeto que escucha y oigamos con atención los siguientes testimonios que ejemplifican lo que decimos:

1: "A saber cómo hacen los destazadores. Los agarran uno por uno. ¡Sólo embrocan al hombre que agarran y, tás, le meten el puñal y lo sacan con sangre y lo lamen, comentando 'sabroso el pollo' " (Falla, 1992, p. i)!

2: "Tiran la gente al hoyo. La gente se va al hoyo y encima echan leña y leña. Riegan gasolina encima. Bien rociada hacen la leña. Se salen de lejos y tiran el fosforito. Cuando cae es como una bomba. ¡Pum!... el gran fuego... Está ardiendo como veinte minutos. La leña todavía se mueve, porque los finados todavía están pataleando. El espíritu está vivo... Y en media hora se termina el fuego. Y los cadáveres quedan pura ceniza” (Falla, 1992, p. i).

Al inicio de este ensayo dijimos que una de nuestras preguntas era qué significa escribir durante la guerra, justamente en el período más doloroso - si es posible pensar que el dolor se puede jerarquizar - de los conflictos armados, como el genocidio guatemalteco, por ejemplo. La reflexión de Falla nos ayuda a conocer tales significados. Para él, escribir sobre las masacres implicaba pensar y documentar a contrapelo de convicciones humanas íntimas, esto es, aquellas que tratan del bien y el mal. Dejar a un lado su convicción de que el ser humano no es capaz de una "deshumanización tan macabra" (1992, p. iii). Era su convicción y la de los testigos mismos, cosa que en más de una ocasión les costó la vida, al no creer que los miembros del ejército fueran realmente capaces de desarrollar tal nivel de carnicería humana. Tal y como él dice, "antes de esa experiencia realmente parecía imposible creer que personas de corazón y carne humana fueran capaces de llegar a esas bestialidades, es decir, a actuar como animales, sin razón, ni compasión” (p. iii). Comunicar las masacres significó entonces despojarse de sus convicciones personales; abrir la brecha entre lo que consideraba posible e imposible, creíble e increíble, humano e inhumano. Falla comparte lo difícil que fue para él y los testigos convencerse de que los seres humanos somos capaces de hacer el mal.

Una vez que el libro sale a luz pública se convierte en un arma de denuncia. "La denuncia grita: ustedes asesinaron al justo" (Falla, 1992, p. iii). Esto nos recuerda lo que en el acápite anterior Martín-Baró calificaba como 'pensamiento subversivo'. Recordándolo y apoyándonos en él podemos afirmar que el pensamiento de Falla es de esta naturaleza. Él mismo califica la tarea de comunicar las masacres como "tremendamente peligrosa" (p. iii) pues, "desata fuerzas sociales que exigen la investigación de los hechos, de los autores materiales e intelectuales de los crímenes, de sus teorías y prácticas contrainsurgentes. Tremendamente peligroso porque enfoca esos años de guerra sucia que fueron los principios de los 80 en Guatemala” (p. iv). 
Aunque se concentra en los años del genocidio - él fue justamente una de los primeros investigadores en nombrar lo ocurrido como genocidio -, la denuncia tiene una historia mucho más larga. En palabras de Falla, "la denuncia cruza los años, las décadas y los siglos" (1992, p. v), "las causas remotas de las masacres han de buscarse muchos siglos atrás" (vi). Aquí el puente al pasado queda establecido en dos direcciones: la primera hila las masacres a nuestro presente; la segunda conecta la violencia colonial con las 'masacres de la selva'. Esto es lo que recurrentemente llamamos pasado-presente, y lo subrayamos porque consideramos que la historización es uno de los principales aportes del pensamiento centroamericano. Es la paradoja de que el pasado pervive en y estructura el presente, pero la comprensión del primero se realiza en el presente y con las preguntas que hoy tenemos a mano.

La forma en que el pasado se manifiesta en el presente ocupa la atención de Falla. Ya hemos mencionado que él plantea su denuncia como una que cruza siglos, por lo que las masacres del presente comparten mucho con "las masacres perpetradas por los conquistadores hace 500 años” (1992, p. vi). Pero recordemos que su palabra es un anuncio de vida, no de muerte. Por eso resalta que de la violencia "ha nacido un pueblo que viene plasmando su identidad en la resistencia, resistencia para vivir y resistencia para ser lo que es" (1992, p. vi). La tensión entre violencia y resistencia es fundamental: es en la pugna de estas dos fuerzas contingentes que encontramos el sujeto de la historia. Falla lo señala al decir que las oleadas populares y la represión forman la historia reciente de Guatemala, entendiendo por ello un conjunto de procesos que arrancan con la revolución de 1944, impulso democratizador interrumpido abruptamente en 1954 por el golpe de Castillo Armas y la invasión norteamericana.

Acontecimientos similares ocurren entre 1954 y 1966, años en que se forman las primeras fuerzas guerilleras después del triunfo cubano y los movimientos religiosos empiezan a coger importancia. Estas resistencias a la colonización moderna terminan con la intervención violenta militar, resultando en la muerte de 9.000 guatemaltecos. Lo que sigue, 1966-82, es el aumento de las fuerzas guerilleras y el comienzo de su trabajo político en la región donde después ocurrieron las masacres. La respuesta estatal fue una campaña de tierra arrasada y las masacres de más de 50.000 guatemaltecos. El último período que delinea Falla es en el que escribe su libro, esto es, el tiempo sangriento del General Lucas García y el General Efraín Ríos Montt, quienes quisieron "quitarle el agua al pez para que el pez muriera" (Falla, 1992, p. xi). Toda esta exposición es importante para Falla porque vincula las voces de su texto con el pasado que les antecedió. Las pone en clara continuidad con la violencia del pasado, regresándonos de nuevo a la noción del pasado-presente. Bien podríamos decir que la presencia del pasado-presente es especialmente notable en la forma que estas voces irrumpen en el presente en el juicio por genocidio a Ríos Montt.

Visto así, la masacre es la culminación, el último capítulo de una larga historia de padecimientos relacionados con la falta de tierra, la migración en busca de trabajo en las costas del país, migrar nuevamente al expandirse la selva como frontera agrícola y quedar sus vidas en una de las zonas más afectadas por el conflicto armado: el Ixcán. La historización nos permite pensar que las violencias extremas siempre existen como una posibilidad latente. Por ello, la puesta en escena de las 
voces afectadas tiene un efecto doble. Por un lado, el gesto ético de Falla es una empatía por el sufrimiento de otros, localizado en un momento histórico específico pero abriendo caminos para que personas que no vivieron la experiencia puedan sentirla, si no como propia, sí cercana. Este es un valor imperecedero pues continúa transmitiéndose hoy a las generaciones que no vivimos este momento - este ensayo es una prueba de ello.

Si el primer efecto es la empatía, el segundo se orienta a la acción. Hay un principio de esperanza: que al escuchar seguirá la lucha por la no repetición de esta historia y por construir 'un mundo otro'. Leámoslo:

Quisiéramos que este libro pudiera documentar y reforzar la voz del pueblo damnificado de Guatemala, para que se respeten los derechos humanos y se construya una sociedad justa donde las estructuras y las instituciones no permitan tales crímenes de lesa humanidad. iQue lo que pasó, nunca más se repita! (Falla, 1992, pp. xi-xii).

Que no se repita y que de las masacres nazcan nuevas semillas de vida, "semillas de aurora". Ese es el clamor de Falla, y "por eso, hemos dicho desde el principio que este libro trae una buena noticia” (1992, p. 229). Aquí Falla nos recuerda a Martín-Baró, quien habla de la negación del "carácter humano del 'enemigo' al que se rechaza como interlocutor y al que se busca destruir" (1988, p. 80). Frente estas actitudes, ambos pensadores identifican la necesidad de una transformación sustantiva de las relaciones sociales.

Las 'semillas auroras' es una imagen crítica de la ética, o mejor dicho, la noética de la guerra. Este último es el término que Nelson Maldonado-Torres utiliza para explicar la ética que se constituyó a partir del encuentro colonial (2007). La conquista del 'Nuevo Mundo' estableció la necesidad de formar lo que Aquille Mbembe (2003) llama un estado de excepción. El encuentro con el otro-amerindio puso al europeo inmediatamente en un modo de guerra, es decir, la forma de relacionarse con el otro es mediada por la enemistad y la violencia. Leamos cómo lo articula MaldonadoTorres: "cuando los conquistadores llegaron a las Américas no aplicaron el código ético que regulaba su comportamiento en sus reinados. Sus acciones eran reguladas por la ética o, más bien, por la no-ética de la guerra" (Maldonado-Torres, 2007, p. 137).

Maldonado-Torres propone que después del encuentro colonial, el estado de excepción fue normalizado para todo el mundo moderno. En este sentido, la no-ética de la guerra fue normalizada y adoptada como la realidad que constituye nuestra modernidad. Esto es lo que él llama la colonialidad del ser. Leamos su descripción:

La ética del ego conquiro deja de ser sólo un código especial de comportamiento, que es legítimo en períodos de guerra, y se convierte en las Américas -y gradualmente en el mundo entero-, por virtud del escepticismo misantrópico, la idea de raza y la colonialidad del poder, en una conducta que refleja la forma como las cosas son (una lógica de la naturalización de diferencias jerarquizadas socialmente, que alcanzará su clímax en el uso de las ciencias naturales para validar el racismo en el siglo XIX) (Maldonado-Torres, 2007, p. 139). 
Esta normalización también ocurrió a nivel del Estado y el Estado soberano adoptó la noción de excepcionalidad. Puede ser ententido, por tanto, como un Estado que transgredió los límites y violó las prohibiciones. Contiene en sí la posibilidad de convertirse en lo que Ileana Rodríguez llama un estado psicóticocriminal (2012). La soberanía aquí no está tan lejos de la perversión y se cimenta sobre la muerte. La posición de Falla, entonces, es una que imagina la política y la soberanía desde la vida, ofreciéndonos otra imagen del pasado, y con ella una intersubjetividad alternativa. Esta apuesta del autor nos demuestra la tremenda sensibilidad y compromiso de un investigador. Su escritura no solo transmite una denuncia de la no-ética del Estado, sino también una voluntad de fe en la vida. Fue esta fe en la vida la que permitió la sobrevivencia y es esta fe la que Falla quiere hacer perdurar: "Gracias a esa fe, que nosotros recibimos y trasladamos a los lectores, en los torrentes de sangre de las masacres, vemos 'densos vinos derramados,' vinos de esperanza, o 'fasto de rubíes' (expresiones de un verso de la poetisa Alaíde)” (1992, p. 229).

\title{
4. Epistemes feministas; (re) escritura del pasado revolucionario: tercera imagen-Ileana Rodríguez
}

\author{
"isomos las mujeres parte de las masas, \\ tropas de guerra, bases sociales, gentes, \\ o no so somos? Si lo somos, ¿de qué maneras? \\ Si no lo somos, ¿qué somos?" \\ (Rodríguez, 1996, p. XIV)
}

En este acápite hablamos de una posicionalidad que se consolidó en los procesos revolucionarios de la región: la feminista. Vale la pena recordar que uno de nuestros propósitos en este ensayo es estudiar cómo la posicionalidad/sensibilidad de los y las pensadoras aporta a la comprensión del pasado conflictivo de la región. Entonces, ¿qué implicaciones tiene la posicionalidad feminista en términos de la comprensión del pasado reciente? ¿qué imagen del pasado nos brinda este pensamiento y qué utilidad tiene para nuestro presente?

Nuestra tesis es que la postura feminista es un lugar de enunciación académica y sensibilidad de vida que ha producido uno de los principales aportes a la comprensión del pasado reciente y, con ello, a la lucha por la democratización de las sociedades centroamericanas. Montserrat Sagot, una destacada intelectual centroamericana, subraya los aportes del movimiento feminista, especialmente al finalizar las guerras y con la firma de los acuerdos de paz que propiciaron la pacificación de la región. Ella afirma que "es imposible pensar en los procesos de democratización de la región sin los aportes del feminismo” (2012, p. 75). A la consideración de Sagot nosotros sumamos el carácter de avanzada del movimiento feminista en la tarea de revisión crítica del pasado reciente que aún estamos realizando en la región. Podemos rastrear, como evidencia de ello, el libro Montañas con recuerdos de mujer (Las Dignas, 1995), una publicación resultado de un encuentro de mujeres centroamericanas y de otras partes del mundo, todas comprometidas con las luchas revolucionarias 
y feministas en Centroamérica. El encuentro fue convocado por la organización salvadoreña Las Dignas. Tanto en los ensayos del libro como en las conversaciones y debates que se transcriben, podemos notar un giro crítico hacia el pasado; una revisión y revaloración del pasado guerrillero y revolucionario, ahora posicionadas como sujeto de género.

El pensamiento feminista que nos interesa es el que se produce en un ejercicio de crítica profunda del proceso revolucionario, que desnuda la dominancia y violencia masculina. La revisión feminista problematiza el proyecto revolucionario de raíz, esto es, discute el proyecto de cambio social a través de la naturaleza de las relaciones que entablan quienes lo llevan adelante. El resultado es una álgida interrogación y puesta en duda de los principales discursos, prácticas, distintivos y órganos representativos de las luchas revolucionarias centroamericanas.

La experiencia revolucionaria, ya sea como intelectual, guerrillera, acompañante, funcionaria, o todas ellas a la vez, dota de un saber que, una vez que existen las condiciones políticas para enunciarlo y compartirlo, interviene sobre el espacio público como una crítica del pasado revolucionario y de la nación que surgiría de tales procesos. Es, por tanto, una intervención cultural que interroga y problematiza las prácticas dominantes que estaban supuestas a caer por las luchas revolucionarias-ien verdad lo estaban?-, pero que continuaron reproduciéndose en una vanguardia masculina ansiosa del canon filial/societal oligárquico y criollo.

La experiencia de las mujeres durante los conflictos armados y las luchas revolucionarias es fundamental para la generación y construcción de conocimiento crítico y posicionamiento del sujeto feminista en la región, así como en la transmisión de este saber a las generaciones que no vivimos los procesos revolucionarios como sujetos activos. Tal y como afirma Sagot, es una irrupción en lo público centroamericano que brinda "importantes aportes para la construcción de una sociedad más justa e incluyente” (2012, p. 79).

En el pensamiento feminista la sujeto intelectual reconoce su lugar de enunciación: se habla como mujer, con las mujeres y desde las mujeres. Desde este lugar de habla, la experiencia feminista pone en público la ausencia de 'empatía', prestando el término de Susan Sontag, y postula la negación de la mujer y la postergación del sujeto de género por parte de las utopías revolucionarias masculinas ${ }^{3}$. Al hablar de empatía, Sontag alude a la incapacidad de tener presente realidades que, aparentemente, no son completamente nuestras (2003, p. 16). En lo que aquí nos interesa, es la incapacidad de tener presente las demandas de las mujeres en los proyectos revolucionarios y, en cambio, alegar su perpetua postergación.

En su ensayo Ante el dolor de los demás (2003), Sontag reflexiona sobre la guerra en diálogo con otra escritora, Virginia Woolf. Sontag se apoya en Tres Guineas, el ensayo de Woolf sobre las raíces de la guerra, para alertarnos acerca de las brechas entre lo femenino y lo masculino en contextos de guerra. Sontag recupera a Woolf cuando dice que, "los hombres emprenden la guerra. A los hombres (a la mayoría) les gusta la guerra, pues para ellos hay en la lucha alguna gloria, una necesidad, una

\footnotetext{
3 Llama la atención que en su libro Revoluciones sin cambios revolucionarios (2011), Edelberto TorresRivas no considere la subalternización de las mujeres dentro de los movimientos revolucionarios como un criterio de análisis para postular que no se produjeron cambios revolucionarios.
} 
satisfacción, que las mujeres (la mayoría) no sienten ni disfrutan” (2003, p. 11). A lo que ella añade lo siguiente: "la guerra es un juego de hombres; la máquina de matar tiene sexo, y es masculino" (2003, p. 14). El pensamiento de Sontag complejiza aún más la problemática que aquí tratamos. El problema no consistiría únicamente en que los hombres no hacen suyas las luchas y demandas de las mujeres, sino que además siguen ejerciendo una 'masculinidad extrema' en los procesos revolucionarios. Este ultimo término es de Jean Franco y con él la autora se refiere a un poder masculino que descansa en la subyugación femenina. En palabras de Franco, "los hombres implacables, todo poderosos, requieren víctimas subyugadas” (2013, p. 15).

El núcleo de la crítica feminista es que con respecto a las relaciones de género, los proyectos revolucionarios reproducen la ideología oligárquica que había caracterizado la historia de la región. Por tanto, su naturaleza revolucionaria es cuestionable y digna de revisión. Tal y como explica Sagot, ésta fue una de las principales contradicciones entre los movimientos feministas y la izquierda, ya que básicamente ésta reprodujo relaciones patriarcales y abusivas en términos de relaciones de género (2012, p. 76).

Queremos ilustrar esta problemática con un valioso trabajo escrito por Ileana Rodríguez, titulado Women, guerrillas and love: understanding war in Central America $(1996)^{4}$. Su libro es un excelente ejemplo para mirar reflexivamente el proceso revolucionario nicaraguense y centroamericano desde una intelectual que piensa como mujer, desde una episteme feminista.

Rodríguez lee críticamente la narrativa centroamericana producida por importantes líderes políticos de la revolución, como Tomás Borge y Sergio Ramírez en Nicaragua, y postula que una búsqueda crítica en los terrenos del discurso literario nos permite ver la perduración de la episteme masculina. La pregunta que dispara la inflexión crítica en su trabajo es, “isomos las mujeres parte de las masas, tropas de guerra, bases sociales, gentes, o no so somos? Si lo somos, ¿de qué maneras? Si no lo somos, ¿qué somos?" (1996, p. XIV). Tal inflexión cuestiona a profundis la naturaleza política y epistémica de los procesos revolucionarios. Pero, ¿fue esta interrogación únicamente dirigida al liderazgo masculino? Por supuesto que no. La pregunta fue más allá y desarmó al Estado nacional como gestor de lo social. Constituyó una interpelación a la formación nacional en su etapa revolucionaria, posicionando las relaciones de género como un criterio sustancial para el análisis de la viabilidad o no de la formación nacional y la partidaria en tanto mediación delegativa y representativa de la misma. Ejemplo de esto último es el gesto de Sofía Montenegro cuando en un ensayo de 1996 se pregunta, "¿es revolucionario el FSLN?" (1996, pp. 31-41). La respuesta de Rodríguez a la pregunta de Montenegro podría ser que no, si por ello entendemos, como señala Rodríguez, que tanto

la vanguardia partidaria, como los líderes políticos de izquierda y los escritores comprometidos, negaron, menospreciaron y marginalizaron a las mujeres, omitiendo todo lo que era sinónimo de mujer. Consecuentemente, las culturas revolucionarias construyeron narrativas

\footnotetext{
4 Llama la atención que en su libro Revoluciones sin cambios revolucionarios (2011), Edelberto TorresRivas no considere la subalternización de las mujeres dentro de los movimientos revolucionarios como un criterio de análisis para postular que no se produjeron cambios revolucionarios.
} 
autoritarias sobre la naturaleza de democracias populares. Entonces, cuando un documento político habla en nombre de la nación, y se escribe en nombre de las personas, uno tiene derecho a preguntarse sobre el estatuto de representación de esa narrativa (1996, p. xv).

Rodríguez interroga las brechas entre los procesos a través de los cuales el guerrillero se constituye como sujeto de la historia, del cambio social, y los contrasta con la manera en que se constituyen las narrativas en torno a las bases sociales, los indigenas, campesinos, mujeres insurgentes. Como bien menciona, la "narrativa de la revolución es una narrativa de la construcción del sujeto guerrillero, devenido luego en vanguardia, partido, líder, y gobierno" (1996, p. xvii).

Su apreciación es que estos sujetos y posicionalidades son configurados desde un Yo masculino, configurando un sujeto colectivo que no incluye a las mujeres, pero aún así posee ánimos de representación de lo colectivo. Rodríguez compara la literatura de las novelas fundacionales estudiadas por Doris Sommer con las de la época revolucionaria escritas por intelectuales de izquierda y líderes de los procesos revolucionarios -tales los casos de Sergio Ramírez y Tomás Borge en Nicaragua, por ejemplo-, señalando que en ambas circunstancias las mujeres son otredad narrativa.

La comparación entre el romanticismo burgués y la narrativa revolucionaria es muy importante porque permite evidenciar que el sujeto de género construido no dista mucho entre uno y otro. A su saber, los escritores/guerrilleros reciclan las ideas de la mujer como 'el ángel del corazón y el hogar', o bien, 'el lugar de descanso de la guerrilla'. La mujer es representada como la apoteosis del deseo masculino (Rodríguez, 1996, p. 33). Para la autora, la literatura de la revolución no reconoce políticamente a la mujer, no la hace parte de la nueva república, de la nueva democracia. La constitución del sujeto revolucionario -bajo el lema del 'Hombre Nuevo'- deviene una copia al carbón del sujeto burgués. En palabras de Rodríguez, "la proyección de las mujeres como el 'reposo del guerrero', o como 'coño revolucionario', revela nuestra exclusión” (1996, p. xviii). Podemos apoyarnos en Franco nuevamente para decir que la centralidad de los hombres -en este caso narrativa/epistémica- se consigue a través de la subalternización y exclusión de las mujeres. Consideremos entonces el pensamiento de Rodríguez no solo como una denuncia pública, sino también como el trazado de una ruta de trabajo: la feminización de las epistemologías como condición de posibilidad de la constitución de verdaderas democracias.

Uno de los argumentos más importantes de parte de Rodríguez a la dirigencia revolucionaria se refiere al vínculo homosocial que sostiene el proyecto de estadonación revolucionario. Esto aporta otro elemento en términos de la continuidad entre el proyecto tradicional dominante y el revolucionario. En su reflexión nos muestra una ternura, una candidez compartida entre los compañeros hombres en armas Carlos Fonseca con los miembros del FSLN, por ejemplo. Mientras los hombres se demuestran ternura entre ellos, la retiran de las mujeres. La idea del 'hombre nuevo' marca una ruta homosocial, por un lado, y por otro una heterosexual orientada a las mujeres en calidad de 'coño revolucionario'. Este doble estándar implica el abandono de las aspiraciones de igualdad, colectividad y democracia (Rodríguez, 1996, p. 34). 
Recordemos que antes dijimos que el núcleo del problema es el ánimo representativo de lo social que tiene el Yo masculino. Es importante no pasarlo por alto porque tal tensión no se manifiesta únicamente con respecto al sujeto de género, sino que alcanza también a las bases sociales. La voluntad representativa, el deseo de hablar por, circula por múltiples discursos, desde los panfletos revolucionarios hasta las revisiones de la historia nacional; desde el espacio literario hasta el político (Rodríguez, 1996, p. 41). El déficit representativo pasa por el sujeto de género pero va también hacia las masas sociales y el guerrillero común, constituyendo también una alteridad masculina irreconciliable que el impulso testimonial que caracterizó estos años no logró resolver. Un ejemplo de esto último es cuando Sergio Ramírez, luego de la derrota electoral de 1990, se pregunta sobre la distancia entre él, como líder de la revolución, y el 'pequeño hombre' de las masas populares. Él registra un conocimiento de la divergencia entre ambas visiones. La pregunta de Ramírez indica la duda en torno a la construcción de las narrativas revolucionarias dirigidas a la construcción del sujeto popular. Entre los sueños de justicia social expresados en la escritura de los líderes, y la vida diaria de las poblaciones campesinas, por ejemplo, hubo una gran distancia. El reciclaje y la prolongación de epistemologías masculinas tradicionales provocó, señala Rodríguez, que los sujetos se encontraran nuevamente en el mapa territorial de un logos falocéntrico.

Rodríguez encuentra algo distinto en Un día en la vida de Manlio Argueta (1986) y No me agarrarán viva de Claribel Alegría y D.J. Flakoll (1983). Publicados al calor de las guerras centroamericanas, nos conducen al proceso salvadoreño. Sagot menciona que en el caso de El Salvador, "la mayoría de las organizaciones feministas surgen al calor de la guerra y de la crisis política, así como de las diferentes facciones del FMLN que combatieron durente el conflicto armado” (2012, p. 79). Para Rodríguez estos textos son ejemplos distintos de lo que significa escribir durante la guerra, o de cómo ésta última puede impactar la escritura y el pensamiento, así como también la constitución del sujeto feminino y/o feminista.

En parte, el aporte de estas dos novelas tiene que ver con una característica que comparten con los estudios de Martín-Baró y Falla: nos dan acceso a las voces de los sujetos de la historia. Ambas novelas forman parte del género testimonial y por lo tanto lo que tenemos son efectivamente las voces de los testimoniantes. En el caso de Argueta, Rodríguez nos dice que su elección de re-presentar las voces de varias mujeres en su novela contribuye a la construcción de un pacto de igualdad entre hombre y mujer. Lo que resuena en esta obra es la voz de la mujer:

en la narrativa de Argueta, es una mujer la que habla: la mujer valida su valor, su autoridad feminina declarando el juicio decisivo, su veredicto condenando las fuerzas de ley y orden (...) la mujer (Lupe, Adolfina, Romelia, María Pía, la madre de Romelia) ocupa un punto central o radical de referencia en una narrativa de nacionalidades en que las voces principales centroamericanas convergen (Rodríguez, 1996, p. 133).

Rodríguez postula que la narrativa centroamericana llegó a su umbral con la novela de Argueta, algo evidenciado por su urgencia y necesidad de representar al subalterno en pleno conflicto bélico. Es la decisión del autor de recoger las palabras- 
aliento de los y las sujetos subalternos que distingue esta novela de los textos de Borge o Ramírez antes comentados. Textos así dejan escuchar las voces de las mujeres como algo más que la masa.

Si los textos 'revolucionarios' del Yo masculino traicionan a los ideales revolucionarios al ignorar la diferencia, la novela de Argueta nos da una alternativa. El devuelve poder a la mujer - tanto político como afectivo. Lo importante es que lo hace no solamente con palabras y narrativa sino también con una "representación corporal del cambio físico que ocurre cuando el cuerpo humano vive este significado y definición [del empoderamiento]" (Rodríguez, 1996, p. 140). Las voces de estas mujeres también nos sugieren otra forma de organización política, ya que ellas no se organizan en el centro (masculino) de la lucha, sino en los laterales y de forma horizontal. La presencia de las voces y corporalidades en esta novela es tan significativa como es lo que Rodríguez define como la política de escritura de Argueta. Es este tipo de escritura que redime, que une subalternidades y nos permite pensar en formas de construir solidaridades que desmienten la dominancia de la episteme liberal-burgués-masculina:

La representación de la subalternidad de estas mujeres, a través de sus propias voces testimoniales, pasado por el colador de la cultura literata de Argueta constituye, en su escritura, la representación política de la posibilidad de frentes culturales en común entre dos tipos de subalternidades, la del campesinado masculino y feminino y la de los intelectuales literatos, la anterior exlcuída de, y la última desilusionada con, la historiografía liberal/colonial de las elites oligárquicas centroamericanas y su concepto de nación (Rodríguez, 1996, p. 135).

Cuerpo y voz siguen siendo lugares centrales para deconstruir la lógica lineal masculina en No me agarrarán viva. Para Rodríguez, esta novela "puede ser leída como una convergencia de voces en un diálogo perpetuo” (1996, p. 163). Desde su perspectiva, contribuye al estudio de la subalternidad presentándonos una lectura de la mujer como una subalternidad central para el texto social. El sujeto de género, en este caso, es integrado a la lucha revolucionaria como un participante en igualdad de condiciones. Hombres y mujeres tienen iguales derechos y también iguales responsabilidades político-militares. Antagoniza entonces la narrativa predominante que pidió a las mujeres esperar y posponer sus propias luchas, ya sea por la 'unidad del bloque revolucionario', por la 'seguridad nacional', u otra razón similar. Una pregunta que surge aquí es si la integración del sujeto de género debía materializarse mediante su masculinización, apropiándose de las prácticas de las masculinidades predominantes, lo que deja abierta la duda sobre la femineidad. Es la misma problemática que Rodríguez describe en Montañas con recuerdos de mujer:

la mujer tiene dos sendas alternas que seguir para lograr su igualdad. La primera es ser igual a los HOMBRES. La segunda es ser diferente. Si es igual, las mujeres son medidas de acuerdo a su correspondencia con el HOMBRE. Si es diferente, de acuerdo a su falta de correspondencia con él. La neutralidad de género es así simplemente el estándar masculino 
porque la masculinidad es referente tanto de la igualdad como de la diferencia (1995, p. 15)

En No me agarrarán viva, todas las mujeres se caracterizan por su capacidad de incorporar en sus cuerpos femeninos todos los adjetivos aplicados en el guerrillero por sí mismo en los ensayos del Che sobre las guerrillas. Pero más que eso nos importa cómo los testimonios debaten la unión de pareja, la maternidad y el amor en el contexto de las insurgencias y organizaciones revolucionarias. En el texto de Alegría no se da por hecho ni se prescribe cómo debe ser la maternidad en los procesos revolucionarios, sino que se discute. Tiene entonces una naturaleza reflexiva, no prescriptiva.

Uno de los aspectos que más destaca Rodríguez sobre este trabajo es la representación de la maternidad revolucionaria. Es una especie de huelga, en términos de que hace a un lado la maternidad individual y la reemplaza por una noción de maternidad colectiva. Esto amplía también la concepción de familia, pues ya no es definida únicamente por "lazos sanguíneos" (Rodríguez, 1996, p. 163). Notemos cómo encontramos aquí, a diferencia del Yo masculino autocentrado, un conjunto de prácticas que trascienden la heroicidad individual y nos proveen de una propuesta epistémica y política de lo común. Rodríguez misma se añade a ella a través de la política y posicionalidad de su escritura y pensamiento. Es su elección en torno a con quiénes pensar y a contrapelo de qué.

\section{Presenciar el pasado, pensar el presente}

$\mathrm{Al}$ inicio de este ensayo nos preguntamos a qué imágenes y voces nos daban acceso estos pensadores, de qué manera nos permitían establecer un puente para presenciar el pasado. Para finalizar queremos reflexionar sobre tales puentes, así como sobre las respuestas y las nuevas preguntas que fuimos encontrando en nuestro propio ejercicio escriturario.

Cada uno de los tres pensadores nos ofrece una imagen del pasado reciente de un país de la región (El Salvador, Guatemala y Nicaragua).

A través de las dos imágenes en lucha sobre la realidad salvadoreña a finales de la década de los 80 -historia oficial vs diariedad-, Martín-Baró nos permitió presenciar el miedo instalado en el cuerpo de las víctimas de la guerra; acercarnos a sus sensaciones corporales desestabilizadas; a las mujeres tratando de evitarse más dolor. Martín-Baró fue la entrada a una de las dimensiones más íntimas de la guerra: el miedo. ¿Cuál es el archivo para penetrar aquî? El cuerpo. En las imágenes que vimos el miedo no es socializado, no es dicho; es únicamente visible en los trastornos del cuerpo. De ahí su propuesta del valor epistémico de las imágenes y no de las palabras, al señalar que no son las 'realidades' las que se cuentan, sino las imágenes. La 'realidad' democrática promulgada por el gobierno norteamericano era desmentida por las imágenes de los cuerpos de las víctimas de la guerra. Aquí la fotografía desempeña un papel fundamental, como lo prueba el trabajo de Susan Meiselas en El Salvador y Nicaragua ${ }^{5}$. La guerra destruye. De eso no hay duda. El

5 En este ensayo no trabajamos el archivo fotográfico pero vale la pena señalar su importancia para futuros trabajos. De Susan Meiselas sobre El Salvador y Nicaragua puede verse: Meiselas (2008a; 2008b). 
pensamiento de Martín-Baró resalta la destrucción psicosocial de la guerra y cómo se deshace el tejido social cuando los antagonismos se llevan al terreno de la guerra.

Falla, por su parte, nos dio acceso a las voces de los testigos de las masacres, a los sobrevivientes de las mismas. Él revela la forma en que la guerra rompe comunidades y elimina vidas. Constituye entonces la posibilidad de presenciar una vida que aún cargaba una intensidad de muerte, pero que era, dijimos antes, la mejor evidencia de la resistencia a tal poder.

Rodríguez nos introdujo a una de las principales contradicciones de los procesos revolucionarios en la región: el horizonte emancipatorio fue limitado a los hombres, no abarcó a las mujeres, quienes a pesar de darse en igualdad de condiciones a la lucha por la democratización, su pensamiento y su cuerpo siguió siendo administrado desde una voluntad masculina, esta vez de izquierda. La contradicción es creativa en términos de que invita, a quienes preguntamos en el presente, a repensar los campos emancipatorios de una revolución o de un cambio social hoy. Nos recuerda, también, la importancia de la micropolítica -la de la casa, la del amor filial, la de la maternidad, la comunitaria- para los grandes cambios sociales.

No solo Martín-Baró tiene al cuerpo como archivo. Una de las características compartidas más importantes del pensamiento de estos tres autores es la decisión de plantear el cuerpo como lugar de memoria. Martín-Baró nos dice que el cuerpo es un archivo que registra la violencia extrema. Falla también plantea el cuerpo como lugar que recibe la violencia y el lugar del cual nace la nueva vida. Para Rodríguez el cuerpo es un marcador de diferencia que produce violencia. Pero es también un archivo desde el cual pensar la deconstrucción de la episteme masculina. Para los tres, el cuerpo no es solo un organismo afectado por la violencia, sino un lugar donde se instala el trauma. El conocimiento del cuerpo trasciende la razón ya que el cuerpo siente, toca y presiente. Al leerlo como archivo de memoria estamos en el terreno de 'otros saberes'.

Hemos dicho que un elemento importante de la política de escritura de estos autores es la denuncia. Pero no olvidemos que es un pensamiento con un profundo espíritu propositivo. Nos invitan a caminar hacia sociedades más democráticas, justas, igualitarias. A pesar de su tremenda fuerza destructiva, la guerra imprimió en ellos una sensibilidad particular que se ve reflejada en sus políticas de escritura. Tal como lo plantea Martín-Baró para el caso del Obispo Romero, "la guerra les ha dado [a Martín-Baró, Falla, Rodríguez] la oportunidad de desarrollar excepcionales virtudes humanas de limpio altruismo y amor solidario" (1988, p. 78).

¿Cuánto resuena aún la idea de Martín-Baró de la guerra como fenómeno definidor del todo social? ¿Nos hemos liberado completamente de ella? ¿Cuánto ha variado el orden de la dominación masculina? Al finalizar las guerras, ¿ha dejado la violación de ser un arma predominantemente masculina, o se han instalado nuevas formas de guerra contra los cuerpos de las mujeres? ¿Qué garantía tenemos de que las 'masacres de la selva' no se repitan hoy, o mañana? ¿Qué justicia le hemos hecho al pasado genocida? Comprender y presenciar el pasado es una labor que emprendemos con la intención de pensar críticamente nuestro presente. El pensamiento producido desde Centroamérica durante los contextos revolucionarios y de guerra que aquí hemos visitado nos permite dialogar críticamente con el pasado, a la vez que nos da 
luces para pensar los cambios que continúan pendientes hoy. La lucha de MartínBaró por desmilitarizar las mentes, incluyendo a las generaciones posteriores a la guerra; la lucha de Falla por la emancipación -las 'semillas auroras'- de la violencia que 'cruza siglos', y la de Rodríguez sobre la feminización de las epistemologías como condiciones para la constitución de verdaderas democracias, son retos absolutamente vigentes hoy. Rodríguez, Martín-Baró y Falla piensan a contracorriente de la razón de Estado - ya de derecha militar, ya de izquierda militar. ¿No es esta misma razón sobre la que hoy nos toca pensar?

\section{Referencias bibliográficas}

Alegría, C. \& Flakoll, D. J. (1983). No me agarrarán viva: la mujer salvadoreña en lucha. México, D.F.: Ediciones Era.

Arendt, H. (2003). Eichmann en Jerusalén: Un estudio sobre la banalidad del mal. Barcelona: Editorial Lumen.

Argueta, M. (1986). Un día en la vida. San Salvador: UCA Editores.

AVANCSO. (2009). Glosas nuevas sobre la misma guerra: Rebelión campesina, poder pastoral y genocidio en Guatemala. Guatemala: Autor.

Ellacuría, I. (1991). La historización del concepto de propiedad como principio de desideologización. En: (s.d.). Veinte años de historia en El Salvador. (pp. 587627). San Salvador: UCA Editores.

Falla, R. (1992). Masacres de la selva. Ixcán, Guatemala (1975-1982). Guatemala: Editorial Universitaria, Universidad de San Carlos de Guatemala.

Franco, J. (2013). Cruel Modernity. Durham, NC: Duke University Press.

Gómez, J. P. \& Hilgert, B. (2014). Razón y pulsión de muerte: violencia política en el pasado reciente de Guatemala. Encuentro, (97), 6-23.

Las Dignas. (1995). Montañas con recuerdos de mujer. San Salvador: Las Dignas.

Lungo, M. (1991). El Salvador en los años 80: Contrainsurgencia y revolución. La Habana: Casa de las Américas.

Maldonado-Torres, N. (2007). Sobre la colonialidad del ser: contribuciones al desarrollo de un concepto. En: S. Castro-Gómez \& R. Grosfoguel (eds.). El giro decolonial: Reflexiones para una diversidad epistémica más allá del capitalismo global. (pp. 127-167). Bogotá: Iesco-Pensar-Siglo del Hombre Editores.

Martín-Baró, I. (1988). La violencia política y la guerra como causas del trauma psicosocial de El Salvador. Revista de psicología de El Salvador, (7), 123-141.

Mbembe, A. (2003). Necropolitics. Public Culture, 15 (1), 11-40.

Meiselas, S. (2008a). In History. ICP, New York, USA.

Meiselas, S. (2008b). Nicaragua June 1978-July 1979. New York: Aperture Foundation. Montenegro, S. (1996). ¿Es revolucionario el FSLN?. En: Las Dignas (eds.). Montañas con recuerdos de mujer. (pp. 31-41). San Salvador: Autor.

Pérez Baltodano, A. (2003). Entre el Estado conquistador y el Estado nación: providencialismo, pensamiento político y estructuras de poder en el desarrollo histórico. Managua: IHNCA-UCA.

Rivera Garza, C. (2008). (Con)jurar el cuerpo: historiar y ficcionar. En: I. Rodríguez \& M. Szurmuk (eds.). Memoria y Ciudadanía. (pp. 169-171). Santiago de Chile: Editorial Cuarto Propio. 
Rodríguez, I. (2012). Operación Pájaro: Expediente 27, 1988. Obispo Gerardi: Enemigo del Estado; marcado para ser eliminado. Revista de Historia. (27), 17-33.

Rodríguez, I. (1996). Women, guerrilla and love: understandaing war in Central America. Minneapolis: University of Minnesota Press.

Sagot, M. (2012). ¿Un paso adelante y dos atrás? La tortuosa marcha del movimiento feminista en la era del neointegrismo y del "fascismo social" en Centroamérica. En: A. Carosio (coord.). Feminismo y cambio social en América Latina y el caribe. (pp. 75-100). Buenos Aires: CLACSO (Colección Grupos de Trabajo).

Schmitt, C. (2007). The concept of the political. Chicago: University of Chicago.

Sontag, S. (2003). Ante el dolor de los demás. Madrid: Alfaguara.

Torres-Rivas, E. (2011). Revoluciones sin cambios revolucionarios: Ensayos sobre la crisis en Centroamérica. Guatemala: F\&G Editores. 